\title{
Linkage Analysis of Depression Spectrum Disease
}

\author{
A.F. Wilson, V.L. Tanna, G. Winokur, R.C. Elston, and \\ E.M. Hill
}

As part of a study of the possible subgroups of unipolar affective disease, 27 families were ascertained as depression spectrum disease (DSD) families. The purpose of this study was an investigation of the linkage relationships between DSD and 30 genetic markers using the robust sib-pair and lod-score methods. Using the sib-pair methods, evidence for linkage was found with orosomucoid (ORM) on chromosome $9 q(p=0.006)$, regardless of whether only individuals with unipolar depression, alcoholism, or antisocial personality were considered to be affected, or whether individuals with any psychiatric disorder were considered to be affected. Weak evidence of linkage with ORM was corroborated using lod-score methods when a narrow definition of depression spectrum disease was used, although stronger evidence of linkage was found with ORM when any psychiatric disorder was considered to be affected. The maximum lod-score for ORM was 1.68 at a male recombination fraction of 0.23 and a female recombination fraction of 0.01 .

\section{Introduction}

The identification of discrete homogeneous disease entities among the broad array of clinical phenotypes that comprise psychiatric illness has been a goal of investigators in psychiatric research for some time. Recently, clinical and genetic heterogeneity within the diagnoses that comprise the affective disorders has been a controversial issue. There have been several attempts to reduce the clinical heterogeneity of psychiatric illness by refining the diagnostic criteria used to classify individuals. Leonhard et al. (1962) demonstrated that there were familial differences in families of manics and depressives. Angst (1966), Perris (1966), and Winokur and Clayton (1967) suggested that primary affective disorders could be separated into bipolar and unipolar depression based on specific kinds of familial and genetic findings. Winokur (1974) further subdivided unipolar depressive disease into depression spectrum disease (DSD) and pure depressive disease (PDD). Here,

From the Department of Biometry and Genetics, Louisiana State University Medical Center, New Orleans, LA (A.F.W., R.C.E); the Department of Psychiatry and Behavioral Science, State University of New York at Stony Brook, Stony Brook, NY, and the Veterans Administration Medical Center, Northport, NY (V.L.T.); the Department of Psychiatry, University of Iowa Hospitals and Clinics, Iowa City, IA (G.W.); and the Department of Psychiatry, University of Michigan Medical Center, Ann Arbor, MI (E.M.H.).

Supported in part by U.S. Public Health Research grant HL28522 from the National Heart, Lung and Blood Institute. by Grant GM28356 from the National Institute of General Medical Sciences, and by the Veterans Administration.

Address reprint requests to Dr. Alexander F. Wilson, Department of Biometry and Genetics, Louisiana State University Medical Center, 1901 Perdido Street, New Orleans, LA 70112-1393.

Received August 29, 1988; revised October 21, 1988. 
we briefly review results from earlier linkage studies of unipolar depression and present the results of a linkage study of DSD.

Depression spectrum disease has been characterized relative to PDD as follows: relatively early age of onset of depression (typically under 40), greater incidence of familial affective disorder, significantly more female than male first-degree relatives with affective disorder, significantly greater familiar alcoholism and antisocial personality, and significantly greater total psychiatric illness (depression, alcoholism, and antisocial personality). The presence of alcoholism and/or antisocial personality has been suggested as a familial marker that can be used to separate depression spectrum disease from among a group of mixed depressives (Winokur et al. 1975; Tanna et al. 1976a). However, controversy exists as to. whether or not alcoholism is part of a broad syndrome, such as DSD, or is a distinct entity with a genetic component separate from that of depression (Merikangas et al. 1985; Schuckit 1985).

The identification of discrete homogeneous disease entities from a broad array of possibly heterogeneous clinical phenotypes can be facilitated with the use of genetic linkage analysis. If a trait can be shown to be linked to a known polymorphic marker locus, then this indicates that the trait has a genetic component. However, if genetic heterogeneity exists, the linkage may be specific to individual families or populations. Bipolar affective disorder, for example, has been found to be linked to markers HRAS1 and INS on the short arm of chromosome 11 in one large Amish family (Kidd et al. 1984; Egeland et al. 1987). However, Hodgkinson et al. (1987) and Detera-Wadleigh et al. (1987) found no evidence of linkage to markers on chromosome 11 in non-Amish families. Other studies have indicated that a gene involved in bipolar affective illness is linked to markers on the X chromosome (Winokur et al. 1969; Baron et al. 1987; Mendlewicz et al. 1987). Rather than being contradictory, these studies suggest that there are at least two loci involved in the genetic etiology of bipolar depression.

Linkage studies of psychiatric disorders have been reviewed in detail by Goldin et al. (1983) and Cox and Suarez (1985). Although linkage analysis has been used in several studies that focused on families of individuals with bipolar depression, or bipolar and unipolar depression, relatively few studies have concentrated on families of individuals with only unipolar depression. Mendlewicz and Fleiss (1974) failed to detect linkage between unipolar depression and either the Xg blood group or protan type color blindness, ruling out X-linked inheritance of unipolar depression. Tanna et al. (1976a) studied 17 polymorphic loci in 14 families ascertained as depression spectrum disease families. Linkage was suggested between DSD and both the $\alpha$-haptoglobin (HP) and third complement component (C3) loci using the sib-pair method (Penrose 1953). In a reanalysis of these data using the methods of Elston and Stewart (1971) and Ott (1974), Tanna et al. (1979) found weak evidence of linkage between DSD and HP (lod-score 1.03) but no evidence of linkage between DSD and the C3 locus. In another analysis, Tanna et al. (1977b) suggested evidence of an association with group-specific component (GC). Crowe et al. (1981) performed a lod-score linkage analysis between DSD and 30 polymorphic markers; there was no suggestion of linkage at any of the loci tested, including $\mathrm{C} 3$ and HP, although a weak association for DSD and GC was noted. Hill et al. (1988) used the robust sib-pair method (Haseman and Elston 1972; Elston et al. 1973) to analyze linkage between various classifications of affective disorders and 24 genetic markers. These data comprised 195 individuals in 25 families; the probands were ascertained as part of the multicenter NIMH Collaborative Depression Study. Among other findings, their results suggested evidence for linkage between DSD and orosomucoid (ORM) and possibly GC. 


\section{Methods}

Families were obtained by screening depressed and/or alcoholic patients at the Iowa City VA Medical Center and the University of Iowa Psychiatric Hospital. The criteria for inclusion in this study required that a family contain at least one individual with primary unipolar depression and at least one first-degree relative with either alcoholism or antisocial personality. Based on these criteria, 25 families were selected as DSD families. To increase the sample size, two additional families that could not be unequivocally classified as either depression spectrum disease or pure depressive disease were also included. In one family, the proband had primary unipolar depression, but a second-degree relative had alcoholism; in the other, the proband had a prior history of alcoholism, but had abstained from alcohol for the previous 10 years. There were a total of 267 individuals.

Members of the patient's family who were at least 14 years of age or older were included in the study; over $90 \%$ of these individuals were personally interviewed by an experienced graduate psychiatric research nurse using a semistructured interview developed at Washington University (Winokur et al. 1971); the remainder were interviewed by telephone. Diagnoses were independently made by two clinical psychiatrists (V.L.T., G.W.) who were blind to the genetic markers and to the diagnosis of the proband. The criteria of Feighner et al. (1972) were used, except that in order to give a single best diagnosis, "probable" diagnoses were considered "definite." Individuals who did not fulfill all the criteria were given diagnoses on the basis of "best clinical judgment" due to the striking history from the subject (and/or relatives) about changes in behavior, personality, functioning and feeling, or difficulties due to drinking, etc. Bereavement or grief reaction was not considered to be an illness.

Blood and saliva were collected from 226 individuals and phenotypes for the following 30 polymorphic genetic markers were determined: ABO, RH, KEL, MNS, P1, FY, JK, PGD, ADA, AK1, ACP1, PGM1, HBB, GPT, C3, HP, TF, GC, ORM, IGHG, IGK, BF, ESD, PR, GLO1, DB, PI, LE, SE, and PA. The nomenclature follows that recommended in McAlpine et al. (1985), with the exception of the determinants at the salivary protein complex (SPC), where the previous nomenclature of PR, PA, and DB is retained.

The diagnoses were as follows: 133 with no psychiatric disorder ( 57 men, 76 women), 56 with unipolar depression ( 18 men, 38 women), 34 with alcoholism ( 31 men, 3 women), 2 with a history of substance abuse other than alcohol ( 1 man and 1 woman), 2 with an undiagnosed psychiatric disorder ( 1 man, 1 woman), and 1 with each of the following: antisocial personality (man), schizophrenia (woman), organic brain syndrome (man), phobic (man), and history of school refusal (woman). There were 35 individuals with unknown affection status. Twenty-two of the 27 identified probands had a diagnosis of unipolar depression and 5 had a diagnosis of alcoholism.

Two methods were used to classify individuals as affected. In the first, individuals with diagnoses of unipolar depression, alcoholism, or antisocial personality were classified as "affected," whereas individuals with any other psychiatric disorder, as well as those individuals with no psychiatric disorder, were classified as "unaffected." Under this scheme, 91 individuals were classified as affected (50 men and 41 women), and 141 individuals were classified as unaffected (61 men and 80 women). In the second, individuals with any psychiatric illness were classified as "affected," and only those individuals with no psychiatric disorder were classified as "unaffected." In this case, there were 99 affected individuals (54 men and 45 women) and 133 unaffected individuals ( 57 men 
and 76 women). Analyses were performed for both of these methods of classification. Initially, two-way chi-square tests for association were used to determine if a significant association exists between affection status and each of the marker loci.

The purpose of this article was an investigation of linkage, as the ascertainment scheme for inclusion of a family in the study was quite complex and traditional methods of segregation analysis were not appropriate. The robust sib-pair method (Haseman and Elston 1972; Elston et al. 1973) was used to screen for linkage relationships between a putative genetic component underlying DSD and any of the 30 polymorphic loci listed above. Linkage was also investigated using approximate lod-score methods. Although the variable age of onset in this disorder can be ignored in the sib-pair method, the parametric lod-score method requires that some assumptions be made about both the mode of inheritance and the age of onset distribution. The method of Bailey-Wilson et al. (1986) was used to determine the form of the age of onset distribution, and additional parameters for the mode of inheritance were obtained by fitting a transmission probability model where age of onset is normally distributed (Elston and Yelverton 1975). The model assumes that there are three types of individuals-AA, Aa, and aa-whose proportions in the population are $q^{2}, 2 q(1-q)$ and $(1-q)^{2}$, respectively. Three transmission probabilities $\tau_{\mathrm{AA} \rightarrow \mathrm{A}}, \tau_{\mathrm{Aa} \rightarrow \mathrm{A}}$, and $\tau_{\mathrm{aar} \rightarrow \mathrm{A}}$, are defined as the probability that an AA, Aa, and aa parent transmits $A$ to their offspring. Under the simple mendelian hypothesis, these probabilities are 1.0,0.5, and 0.0, respectively. Individuals of type AA (under a recessive model), and individuals of types AA and Aa (under a dominant model), are assumed to have a probability $\gamma$ of being susceptible to DSD, and all other individuals are assumed to be not susceptible.

Although it was not practical to allow for the method by which the families were ascertained in any rigorous manner, the likelihood of the data under the above model was conditioned on the likelihood of the phenotype of the proband (assuming only one proband per family) as an approximation (Majumder 1985). The likelihood was maximized over all unknown parameters, without any restrictions and under the following restrictive hypotheses: (1) $\tau_{\mathrm{AA}}=1, \tau_{\mathrm{Aa}}=0.5, \tau_{\mathrm{aa}}=0.0$ : a "mendelian" hypothesis; and (2) $\tau_{\mathrm{AA}}$ $=\tau_{\mathrm{Aa}}=\tau_{\mathrm{aa}}$ : an "environmental" hypothesis. Twice the decrease in the natural logarithm of the likelihood was then compared to a chi-square distribution to test for significant departure from each hypothesis.

Using the parameter estimates obtained for the best fitting monogenic mendelian model found, lod-score linkage analyses between the putative gene for DSD and each of the polymorphic marker loci were performed using pedigree analysis methods (Elston and Stewart, 1971; Ott 1974,1985). $\log _{10}$ likelihoods for male and female recombination fractions of $0.0,0.1,0.2,0.3$, and 0.4 were computed and expressed as lod-scores relative to the $\log _{10}$ likelihood for independent recombination, allowing for a uniform age of onset distribution (Hodge et al. 1979). As the method of estimation used was appropriate only for families ascertained through single probands, the gene frequency was expected to be overestimated. Therefore, the estimate of the gene frequency $(q)$ was reduced by a factor of 10 . It was verified that a difference of this magnitude in the assumed gene frequency had little effect on the results.

\section{Results}

Two markers, transferrin (TF) and hemoglobin- $\beta$ (HBB), were not polymorphic and were not included in the analyses. When only individuals with unipolar depression, alcoholism, or antisocial personality were considered to be affected, no marker-disease associations 
Table 1. Results of Sib-pair Linkage Analyses Between Depression Spectrum Disease and ORM, Including (1) Only Unipolar Depression, Alcoholism, or Antisocial Personality as Affected, and (2) Any Psychiatric Illness as Affected

\begin{tabular}{ccccc}
\hline & \multicolumn{3}{c}{$\begin{array}{c}\text { Mean estimated proportion of marker } \\
\text { genes shared identical by descent }\end{array}$} \\
\cline { 3 - 5 } & $\begin{array}{c}\text { Concordant versus } \\
\text { discordant pairs } \\
p \text {-value }\end{array}$ & $\begin{array}{c}0 \text { Sibs } \\
\text { affected }\end{array}$ & $\begin{array}{c}1 \text { Sib } \\
\text { affected }\end{array}$ & $\begin{array}{c}2 \text { Sibs } \\
\text { affected }\end{array}$ \\
\hline$(1)$ & 0.006 & $0.56^{b}$ & 0.48 & 0.52 \\
$(2)$ & 0.006 & $0.55^{b}$ & 0.48 & $0.53^{a}$ \\
\hline
\end{tabular}

$a^{a} 0.01<p \leqslant 0.05,{ }^{b} p \leqslant 0.01$, based on one-tail $t$-tests for significant deviation from 0.5 .

were found to be significant after allowing for the multiple tests performed. The mean estimated proportion of marker genes that sib-pairs share identical by descent (i.b.d.) was significantly less for discordant pairs than for the concordant pairs for only the orosomucoid (ORM) locus ( $p<0.006$, after allowing for 28 multiple comparisons), and the mean proportions of genes i.b.d. had the pattern expected in the case of linkage (Table 1). When individuals with any psychiatric illness were considered to be affected, the results were similar (Table 1). Regardless of how affection status was defined, the sib-pair analysis did not detect linkage with HP, which was previously suggested as a possible linkage with weak evidence (Tanna et al. 1976a,1979); $p$-values were greater than 0.9 and 0.7 for only DSD and any psychiatric illness, respectively.

Results of fitting transmission probability models are presented in Table 2 . Given the relatively small sample size, the difficulty in properly allowing for the mode of ascertainment, and the fact that some of the parameter estimates occurred at boundary values

Table 2. Maximum likelihood estimates, chi-square values, and degrees of freedom for 27 depression spectrum disease families analyzed under the transmission probability model (1) including only unipolar depression, alcoholism, or antisocial personality as affected and (2) including any illness as affected

\begin{tabular}{|c|c|c|c|c|c|c|c|c|}
\hline \multirow[b]{2}{*}{ Hypothesis } & \multicolumn{3}{|c|}{$\begin{array}{l}\text { Transmission } \\
\text { probabilities }\end{array}$} & \multirow{2}{*}{$\begin{array}{c}\text { Gene } \\
\text { frequency } \\
q\end{array}$} & \multirow{2}{*}{$\begin{array}{c}\text { Susceptibility } \\
\gamma\end{array}$} & \multicolumn{2}{|c|}{ Age of onset } & \multirow{2}{*}{$\begin{array}{c}\text { Chi-square } \\
\text { (df) }\end{array}$} \\
\hline & $\tau_{\text {AA }}$ & $\tau_{\mathrm{Aa}}$ & $\tau_{\mathrm{aa}}$ & & & Mean & SD & \\
\hline \multicolumn{9}{|l|}{ (1) } \\
\hline Unrestricted & 1.000 & 0.860 & 0.052 & 0.178 & 0.627 & 36.85 & 13.89 & \\
\hline $\begin{array}{l}\text { Mendelian } \\
\text { dominant }\end{array}$ & 1.000 & 0.500 & 0.000 & 0.119 & 0.849 & 36.26 & 14.04 & $\begin{array}{l}2.574 \\
(2-3)\end{array}$ \\
\hline $\begin{array}{l}\text { Mendelian } \\
\quad \text { recessive }\end{array}$ & 1.000 & 0.500 & 0.000 & 0.984 & 0.474 & 35.89 & 14.12 & $\begin{array}{c}6.146 \\
(2-3)\end{array}$ \\
\hline Environmental & 0.383 & 0.383 & 0.383 & 0.236 & 0.823 & 36.26 & 14.03 & $\begin{array}{c}3.551 \\
(1-2)\end{array}$ \\
\hline \multicolumn{9}{|l|}{ (2) } \\
\hline Unrestricted & 1.000 & 0.877 & 0.019 & 0.101 & 0.685 & 35.95 & 14.21 & \\
\hline $\begin{array}{l}\text { Mendelian } \\
\quad \text { dominant }\end{array}$ & 1.000 & 0.500 & 0.000 & 0.091 & 0.923 & 35.47 & 14.27 & $\begin{array}{c}3.432 \\
(2-3)\end{array}$ \\
\hline $\begin{array}{l}\text { Mendelian } \\
\text { recessive }\end{array}$ & 1.000 & 0.500 & 0.000 & 0.882 & 0.570 & 36.64 & 14.17 & $\begin{array}{r}10.438^{a} \\
\quad(2-3)\end{array}$ \\
\hline Environmental & 0.375 & 0.375 & 0.375 & 0.209 & 0.911 & 35.47 & 14.28 & $\begin{array}{r}6.813^{a} \\
(1-2)\end{array}$ \\
\hline
\end{tabular}


rather than at local maxima of the likelihood surface, twice the decrease in log likelihood cannot be considered to be distributed exactly as chi-square. Nevertheless, the fit of the various hypotheses can be approximately gauged by comparing these "chi-square" values to chi-square distributions corresponding to the degrees of freedom given in Table 2. Regardless of whether or not individuals with psychiatric disorders other than unipolar depression, alcoholism, or antisocial personality were considered to be affected, the mendelian dominant hypothesis clearly was the best fit. The parameter estimates were similar to those reported by Tanna et al. (1979), who assumed a log-normal age of onset distribution.

The age of onset plots are given in Figure 1, where the scale for the vertical axis is arbitrary (see Bailey-Wilson et al. 1986). As the sample contained only one unaffected individual with age at examination later than 60 years old, the three outlying individuals with ages of onset after 60 years old were not included in the plots. The points on this plot can be approximately fitted by either a cumulative normal distribution or a cumulative uniform distribution. The lod-score linkage analyses assumed a dominant mode of inheritance for the susceptibility gene, with a linear cumulative age of onset distribution. For DSD, the penetrance was taken to be 0.0 below 13 years of age and 0.849 after 61 years of age, increasing linearly between these two ages. For any psychiatric illness, the penetrance was assumed to rise linearly from 0.0 at age 11.5 years to 0.923 at 61 years of age.

Results of the lod-score linkage analyses between DSD and the 28 polymorphic marker loci, constraining the male and female recombination fractions to be equal, are presented in Table 3. Linkage was excluded (lod-score less than or equal to -2.0 ) at a recombination fraction of 0.0 for 15 systems and at a recombination fraction of 0.10 for 5 systems. Weak evidence of linkage was found with ORM. A maximum lod-score of 1.29 was found at a recombination fraction of 0.0 . When male and female recombination fractions were allowed to be different, the maximum lod-score was approximately 1.46 at a male recombination fraction of 0.29 and a female recombination fraction of 0.01 . This difference was not significant $(p=0.56)$. The analysis was repeated using sex-specific penetrances calculated from the number of affected men and women after adjusting for the number of probands. Taking the maximum penetrances to be 0.936 and 0.777 for men and women, respectively, with male and female recombination fractions constrained to be equal, the maximum lod-score increased from 1.29 to only 1.34 at a recombination fraction of 0.0 . This difference was smaller than that of the nonsignificant result noted above.

Results of the lod-score linkage analyses for any psychiatric disorder, again constraining the male and female recombination fractions to be equal, are presented in Table 4. Linkage was excluded for 17 systems at a recombination fraction of 0.0 and for 7 systems at a recombination fraction of 0.10 . However, somewhat stronger evidence for linkage was found with ORM than before. Using quadratic interpolation, a maximum lod score of 1.45 was found at a recombination fraction of 0.05 for ORM. When male and female recombination fractions were allowed to be different, the maximum lod-score for ORM was 1.68 at a male recombination fraction of 0.23 and a female recombination fraction of 0.01. Again, this difference was not significant $(p=0.50)$. Similarly, for sex-specific maximum penetrances taken to be 0.990 and 0.868 , the maximum lod-score increased from 1.45 to 1.50 at a recombination fraction of 0.0 .

Changing the frequency of the disease allele had virtually no effect on the lod-scores. When only unipolar depression, alcoholism, and antisocial personality were considered 
a)

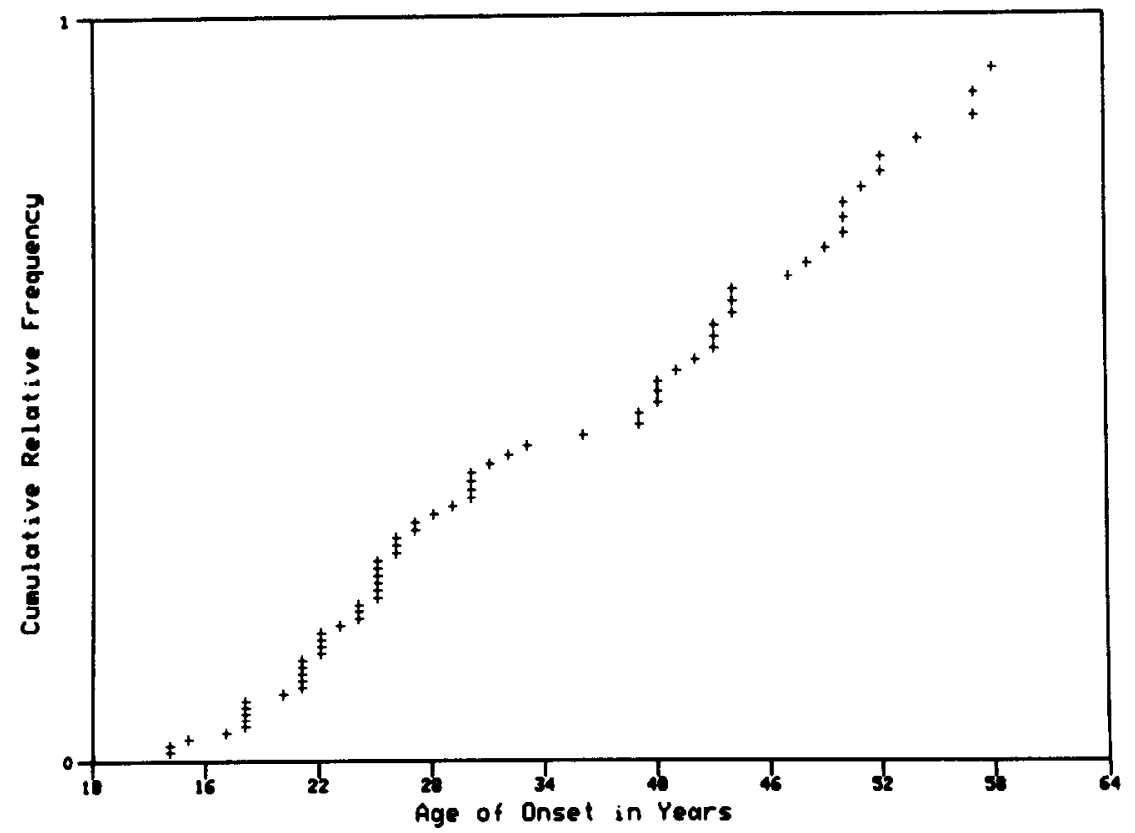

b)

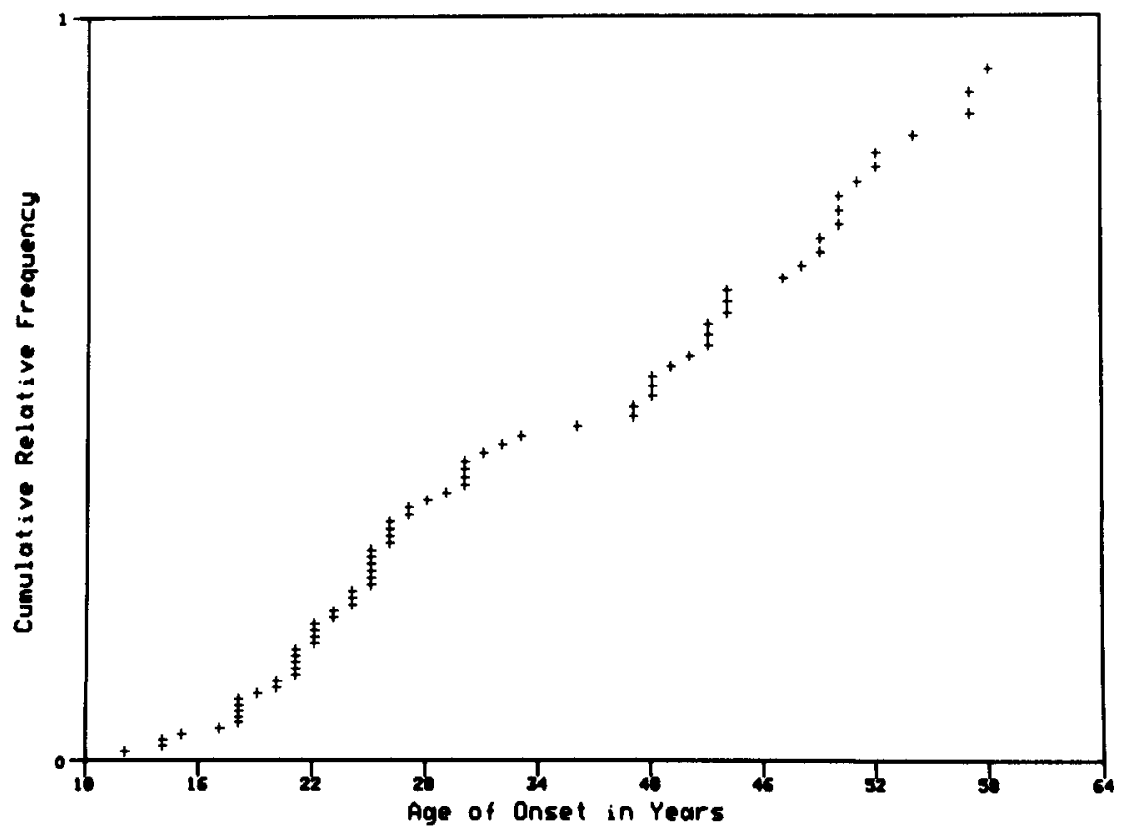

Figure 1. Empirical cumulative plot of the ages of onset adjusted for the variable ages at examination for (a) individuals with depression, alcoholism, or antisocial personality considered to be affected, and (b) individuals with any psychiatric disorder considered to be affected. The vertical scale is arbitrary. 
Table 3. Lod-Scores from Linkage Analysis between Depression Spectrum Disease and 28 Polymorphic Marker Loci

\begin{tabular}{lcrrrrr}
\hline & & \multicolumn{5}{c}{ Recombination fraction } \\
\cline { 3 - 7 } \multicolumn{1}{c}{ Marker } & Location & 0.0 & 0.1 & 0.2 & \multicolumn{1}{c}{0.3} & \multicolumn{1}{c}{0.4} \\
\hline GPT & & -10.841 & -2.510 & -0.904 & -0.255 & -0.034 \\
KEL & & -0.480 & -0.276 & -0.141 & -0.058 & -0.014 \\
PGD & $1 \mathrm{p}$ & 0.457 & 0.368 & 0.310 & 0.213 & 0.097 \\
RH & $1 \mathrm{p}$ & -9.529 & -1.448 & -0.086 & 0.220 & 0.098 \\
PGM1 & 1p & -2.432 & -0.025 & 0.409 & 0.356 & 0.139 \\
FY & $1 \mathrm{l}$ & -0.997 & -0.281 & -0.052 & -0.016 & -0.038 \\
ACP1 & $2 \mathrm{p}$ & -6.850 & -1.238 & -0.365 & -0.086 & -0.037 \\
IGK (KM) & $2 \mathrm{p}$ & 0.050 & -0.096 & -0.123 & -0.087 & -0.037 \\
JK & 2 & -2.205 & -0.898 & -0.389 & -0.137 & -0.024 \\
GC & $4 \mathrm{q}$ & -9.832 & -3.817 & -1.696 & -0.669 & -0.200 \\
MNS & $4 \mathrm{q}$ & -9.494 & -1.906 & -0.282 & 0.152 & 0.100 \\
BF & $6 \mathrm{p}$ & -3.834 & -1.386 & -0.503 & -0.158 & -0.058 \\
GLO1 & $6 \mathrm{p}$ & -1.086 & 0.159 & 0.510 & 0.402 & 0.136 \\
ORM & $9 \mathrm{q}$ & 1.293 & 1.167 & 0.966 & 0.599 & 0.189 \\
AK1 & $9 \mathrm{q}$ & -0.559 & -0.291 & -0.148 & -0.061 & -0.015 \\
ABO & $9 \mathrm{q}$ & -6.189 & -2.034 & -0.735 & -0.221 & -0.041 \\
DB & $12 \mathrm{p}$ & -0.663 & -0.210 & -0.010 & 0.058 & 0.049 \\
PA & $12 \mathrm{p}$ & -1.284 & -0.816 & -0.401 & -0.156 & -0.035 \\
PR & $12 \mathrm{p}$ & -4.081 & -0.897 & -0.328 & -0.099 & -0.020 \\
ESD & $13 \mathrm{q}$ & -1.644 & -0.435 & -0.034 & 0.047 & 0.003 \\
PI & $14 \mathrm{q}$ & -3.845 & -1.560 & -0.456 & 0.000 & 0.078 \\
IGHG (GM) & $14 \mathrm{q}$ & -6.203 & -2.641 & -1.063 & -0.329 & -0.055 \\
HP & $16 \mathrm{q}$ & -10.060 & -2.943 & -1.252 & -0.447 & -0.091 \\
C3 & 19 & -5.724 & -0.445 & 0.120 & 0.176 & 0.068 \\
LE & 19 & -0.384 & -0.157 & -0.067 & -0.025 & -0.005 \\
SE & 19 & -1.626 & -0.450 & -0.169 & -0.048 & -0.003 \\
ADA & $20 \mathrm{q}$ & -0.717 & -0.413 & -0.124 & 0.013 & 0.038 \\
P1 & 22 & -3.374 & -0.908 & -0.133 & 0.072 & 0.049 \\
\hline & & & & & &
\end{tabular}

to be affected, for example, the lod-scores at a male recombination fraction of 0.30 and a female recombination fraction of 0.01 , were $1.43,1.46$, and 1.46 for disease allele frequencies of $0.12,0.012$, and 0.001 , respectively. Linkage results between DSD and ORM for the two families that could not be unequivocally classified as DSD families were specifically examined and found to be virtually noninformative.

\section{Discussion}

In this study, the robust sib-pair method and the lod-score method were used to determine if linkage could be found between DSD and 28 polymorphic marker loci. The analysis suggests that there may be a gene closely linked to the orosomucoid (ORM) locus involved in the etiology of DSD. The odds in favor of linkage are about 29 to 1 . The odds in favor of linkage are somewhat higher, about 48 to 1 , when individuals with any psychiatric illness are considered to be affected in addition to individuals with depression, alcoholism, or antisocial personality. This may indicate that a genetic component is involved in a phenotype with a broader spectrum of psychiatric disease than DSD. 
Table 4. Lod-Scores from Linkage Analysis between Any Psychiatric Disease in Depression Spectrum Disease Families and 28 Polymorphic Marker Loci

\begin{tabular}{lcrrrrr}
\hline & & \multicolumn{5}{c}{ Recombination fraction } \\
\cline { 3 - 7 } \multicolumn{1}{c}{ Marker } & Location & \multicolumn{1}{c}{0.0} & 0.1 & \multicolumn{1}{c}{0.2} & 0.3 & \multicolumn{1}{c}{0.4} \\
\hline GPT & & -11.901 & -2.443 & -0.805 & -0.198 & -0.020 \\
KEL & & -1.008 & -0.627 & -0.335 & -0.143 & -0.035 \\
PGD & $1 \mathrm{p}$ & 0.523 & 0.426 & 0.361 & 0.246 & 0.107 \\
RH & $1 \mathrm{p}$ & -8.077 & 0.063 & 0.837 & 0.695 & 0.232 \\
PGM1 & $1 \mathrm{p}$ & -5.017 & -0.422 & 0.341 & 0.398 & 0.166 \\
FY & 1 & -1.348 & -0.494 & -0.162 & -0.064 & -0.051 \\
ACP1 & $2 \mathrm{p}$ & -9.714 & -2.100 & -0.801 & -0.267 & -0.080 \\
IGK & $2 \mathrm{p}$ & -0.111 & -0.173 & -0.157 & -0.108 & -0.051 \\
JK & 2 & -2.445 & -0.869 & -0.355 & -0.117 & -0.019 \\
GC & $4 \mathrm{q}$ & -11.219 & -4.207 & -1.941 & -0.779 & -0.233 \\
MNS & $4 \mathrm{q}$ & -10.308 & -2.254 & -0.344 & 0.195 & 0.131 \\
BF & $6 \mathrm{p}$ & -4.622 & -1.586 & -0.506 & -0.107 & -0.032 \\
GLO1 & $6 \mathrm{p}$ & -0.134 & 0.810 & 1.105 & 0.819 & 0.287 \\
ORM & $9 \mathrm{q}$ & 1.428 & 1.430 & 1.259 & 0.810 & 0.266 \\
AK1 & $9 \mathrm{q}$ & -0.651 & -0.321 & -0.144 & -0.052 & -0.011 \\
ABO & $9 \mathrm{q}$ & -7.211 & -2.557 & -1.001 & -0.325 & -0.064 \\
DB & $12 \mathrm{p}$ & -1.278 & -0.565 & -0.196 & -0.022 & 0.028 \\
PA & $12 \mathrm{p}$ & -1.456 & -0.918 & -0.463 & -0.182 & -0.041 \\
PR & $12 \mathrm{p}$ & -6.883 & -1.247 & -0.462 & -0.144 & -0.029 \\
ESD & $13 \mathrm{q}$ & -2.986 & -0.342 & 0.163 & 0.214 & 0.087 \\
PI & $14 \mathrm{q}$ & -4.691 & -1.615 & -0.313 & 0.154 & 0.160 \\
IGHG & $14 \mathrm{q}$ & -9.013 & -3.483 & -1.453 & -0.472 & -0.084 \\
HP & $16 \mathrm{q}$ & -10.008 & -2.568 & -0.782 & -0.131 & 0.012 \\
C3 & 19 & -7.072 & -1.362 & -0.349 & -0.010 & 0.041 \\
LE & 19 & -0.616 & -0.182 & -0.066 & -0.022 & -0.005 \\
SE & 19 & -1.721 & -0.292 & -0.035 & 0.041 & 0.036 \\
ADA & $20 \mathrm{q}$ & -3.192 & -1.223 & -0.552 & -0.204 & -0.044 \\
P1 & 22 & -3.662 & -1.781 & -0.675 & -0.173 & -0.002 \\
\hline & & & & & &
\end{tabular}

The suggestion of linkage was corroborated with both the sib-pair and lod-score methods. Although the sib-pair method does not require an assumption of monogenic inheritance or knowledge of any of the parameters specifying either the mode of inheritance or age of onset distribution, the lod-score method requires that assumptions be made concerning the mode of inheritance, gene frequency, and age of onset distributionparameters estimated from segregation analysis. However, the sib-pair method will only detect linkage, whereas the lod-score method provides a measure of the odds in favor of linkage (lod-score) and estimates the recombination fraction between linked loci. It should also be noted that the significance level for the sib-pair method is usually adjusted to allow for multiple comparisons, whereas the analogous $p$-value for the traditional lodscore method is not similarly adjusted. For example, when any psychiatric illness is considered to be affected, the unadjusted $p$-values are 0.0002 and 0.005 for the sib-pair and lod-score methods, respectively; after allowing for multiple comparisons, these $p$ values become 0.006 and 0.13 , respectively. We do not yet know enough about the robustness and power of these two statistical methods to interpret the difference in these significance levels. 
In addition to ORM, adenylate kinase (AK1) and the $\mathrm{ABO}$ blood group are also located on chromosome $9 \mathrm{q}$. Moving distally from the centromere, the order of the loci is thought to be ORM-AK1-ABO, and the estimated recombination fractions are ORM-AK1 0.30, AK1-ABO 0.18, and ORM-ABO 0.34 (Meera Khan and Smith 1984). The families were relatively uninformative for $\mathrm{AK} 1$, and linkage was excluded up to a recombination fraction of 0.1 with the $A B O$ locus. Given the relatively large recombination fraction between ORM and $A B O$, this negative finding is not inconsistent with a linkage to the ORM locus. A large proportion of the families in this study were not informative for linkage between DSD and ORM. At a recombination fraction of $0.0,16$ families had lod-scores between -0.1 and $0.1,6$ families had lod scores $\geqslant 0.1$ (the largest being 1.32), and 5 families had lod scores $\leqslant-0.1$ (the smallest being -0.88 ). The number of informative and uninformative families was similar when any psychiatric illness was classified as affected.

The study by Hill et al. (1988) has replicated the main finding of this article. They found evidence for linkage between DSD and ORM ( $p=0.008$, not allowing for multiple comparisons), although the criteria for classification as affected were somewhat different. When this result is adjusted for multiple comparisons $(p=0.175)$ and combined with the $p$-value from the present study, the overall adjusted $p$-value can be determined by comparing $-2 \cdot \Sigma \ln p$ to a $\chi^{2}$ distribution with 4 degrees of freedom (Fisher 1950). The overall $p$-value for these two studies combined is then $<0.01$. Similarly, when the $p$ value from the suggested linkage of DSD and HP (Tanna et al. 1976a) is combined with the corresponding $p$-value from the present study the overall $p$-value is not significant ( $p$ $>0.1$ ).

Further studies may uncover linkages specific to other subgroups of affective disorder. However, we should not be surprised if there are genes predisposing individuals to psychosis in general, as suggested by Karlsson (1985) to explain the genetic basis for schizophrenia in large Icelandic pedigrees. It is interesting to note that a number of reports have suggested linkage (or association) of different psychiatric disorders to two groups of linked markers, the ABO-DBH-AK1-ORM loci on the long arm of chromosome 9 and the GC and MNS loci (recombination fraction of $0.42 ;$ B.J.B. Keats, personal communication) on the long arm of chromosome 4 . In addition to the results of the present study, Tanna et al. (1988) suggest weak evidence of linkage of pure depressive disease with $A B O$ and MNS, and Böök et al. (1978) noted an association between schizophrenia and low value of dopamine- $\beta$-hydroxylase $(\mathrm{DBH})$, which has recently been shown to be linked to the ABO locus (Wilson et al. 1988). Slater and Ziskind (1973) found an association between female psychiatric patients and the GC " 2 " allele; Tanna et al. (1977b) suggested an association between DSD and the GC "1" allele; and Böök et al. (1978) noted an association between schizophrenia and the GC "2" allele in a single large pedigree. In a linkage analysis involving dizygotic twin pairs, the most significant result found by Elston et al. (1973) was that of a linkage between GC and hospitalized psychosis. In other studies, Tanna et al. (1976b,1977a) suggested weak evidence for linkage of PDD and GC; Johnson et al. (1981) found weak evidence of linkage between bipolar and unipolar depression of GC; Hill et al. (1988) found weak evidence for linkage between GC and DSD; and Goldin et al. (1983) found weak evidence of linkage between bipolar affective disorder and MNS.

Although a few studies have excluded tight linkage between various psychiatric disorders and the ABO, ORM, GC, and MNS loci (Crowe et al. 1981; Johnson et al. 1981), direct comparisons between these studies are difficult because of different diagnostic 
criteria, different schemes for classifying individuals as affected, and differences in the methods of analysis, especially with respect to age of onset and reduced penetrance. In any case, the very number of studies that have presented weak evidence of linkage or association to these two groups of linked loci is intriguing and would appear to warrant further linkage studies involving a more complete set of polymorphic markers on the long arm of chromosome 9 and the long arm of chromosome 4 .

\section{References}

Angst J (1966): Zur Atiologie und Nosologie endogener depressiver Psychosen. Berlin: Springer. Bailey-Wilson JE, Elston RC, Schuelke GS, Kimberling W, Albano W, Lynch JF, Lynch HT (1986): Segregation analysis of hereditary nonpolyposis colorectal cancer. Genet Epidemiol 3:27-38.

Baron M, Risch N, Hamburger R, Mandel B, Kushner S, Newman M, Drumer D, Belmaker RH (1987): Genetic linkage between X-chromosome markers and bipolar affective illness. Nature 326:289-292.

Böök JA, Wetterberg L, Modrzewaka K (1978): Schizophrenia in a north Swedish gengraphical isolate 1900-1977. Epidemiology, genetics and biochemistry. Clin Genet 14:373-394.

Cox NJ, Suarez BK (1985): Linkage analysis for psychiatric disorders. II. Methodological considerations. Psychiatr Dev 4:369-382.

Crowe RR, Namboodiri KK, Ashby HB, Elston RC (1981): Segregation and linkage analysis of a large kindred of unipolar depression. Neuropsychobiology 7:20-25.

Detera-Wadleigh SD, Berrettini WH, Goldin LR, Boorman D, Anderson S, Gershon ES (1987): Close linkage of $c$-harvey-ras- 1 and the insulin gene to affective disorder is ruled out in three North American pedigrees. Nature 325:806-808.

Egeland JA, Gerhard DS, Pauls DL, Sussex JN, Kidd KK, Allen CR, Hostetter AM, Housman DE (1987): Bipolar affective disorders linked to DNA markers on chromosome 11. Nature 325:783-787.

Elston RC, Stewart J (1971): A general model for the genetic analysis of pedigree data. Hum Hered 21:523-542.

Elston RC, Yelverton KC (1975): General models for segregation analysis. Am J Hum Genet 27:3145.

Elston RC, Kringlen E, Namboodiri KK (1973): Possible linkage relationships between certain blood groups and schizophrenia or other psychoses. Behav Genet 2:101-106.

Feighner JP, Robins E, Guze SB, Woodruff RA Jr, Winokur G, Munoz R (1972): Diagnostic criteria for use in psychiatric research. Arch Gen Psychiatry 26:57-63.

Fisher RA (1950): Statistical Methods for Research Workers (ed 11). Edinburgh and London: Oliver and Boyd, pp 99-101.

Goldin LR, Gershon ES, Targum SD, Sparkes RS, McGinnis M (1983): Segregation and linkage analyses in families of patients with bipolar, unipolar, and schizoaffective mood disorders. Am $J$ Hum Genet 35:274-287.

Haseman JK, Elston RC (1972): The investigation of linkage between a quantitative trait and a marker locus. Behav Genet 2:3-19.

Hill EM, Wilson AF, Elston RC, Winokur G (1988): Evidence for possible linkage between genetic markers and affective disorders. Biol Psychiatry 24:903-917.

Hodge SE, Morton LA, Tideman S, Kidd KK, Spence MA (1979): Age of onset correction available for linkage analysis (LIPED). Am J Hum Genet 31:761.

Hodgkinson S, Sherrington R, Gurling H, Marchbanks R, Reeders S, Mallet J, McInnis M, Petursson H, Brynjolfsson $J$ (1987): Molecular genetic evidence for heterogeneity in manic depression. Nature 325:805-806.

Johnson GFS, Hunt GE, Robertson S, Doran TJ (1981): A linkage study of manic-depressive 
disorders with HLA antigens, blood groups, serum proteins, and red cell enzymes. $J$ Affective Disord 3:43-58.

Karlsson JL (1985): Genetics of schizophrenia. Intgr Psychiatry 3:52-62.

Kidd KK, Egeland JA, Molthan L, Pauls DL, Kruger SD, Messner KH (1984): Amish study IV: Genetic linkage study of pedigrees of bipolar probands. Am J Psychiatry 141:1042-1048.

Leonhard K, Korff I, Schulz H (1962): Die termperament in den familien der monopolaren und bipolaren phasischen psychosen. Psychiat Neurol 143:416-434.

Majumder PP (1985): Comparison of ascertainment-bias correction schemes for pedigrees ascertained through multiple probands. Statist Med 4:163-173.

McAlpine PJ, Shows TB, Miller RL, Pakstis AJ (1985): The 1985 catalog of mapped genes and the report of the nomenclature committee. Cytogenet Cell Genet 40:360-489.

Meera Khan P, Smith M (1984): Report of the committee on the genetic constitution of chromosomes 7, 8 and 9. Human Gene Mapping 7 (1984): Seventh international workshop on human gene mapping. Cytogenet Cell Genet 37:71-102.

Mendlewicz J, Fleiss JL (1974): Linkage studies with X-chromosome markers in bipolar (manicdepressive) and unipolar (depressive) illness. Biol Psychiatry 9:261-264.

Mendlewicz J, Simon P, Sevy S, Charon F, Brocas H, Legros S, Vassar G (1987): Polymorphic DNA marker on X chromosome and manic depression. Lancet i:1230-1232.

Merikangas KR, Leckman JF, Prusoff BA, Pauls DL, Weissman MM (1985): Familial transmission of depression and alcoholism. Arch Gen Psychiatry 42:367-372.

Ott $J$ (1974): Estimation of the recombination fraction in human pedigrees: Efficient computation of the likelihood for human linkage studies. Am J Hum Genet 26:588-597.

Ott J (1985): Analysis of Human Genetic Linkage. Baltimore: John Hopkins.

Penrose LS (1953): The general purpose sib-pair linkage test. Ann Eugen 18:120-124.

Perris C (1966): A study of bipolar (manic depressive) and unipolar recurrent depressive psychoses. Acta Psychiatr Scand 42 (Suppl. 194) pp 1-189.

Schuckit MA (1985): Genetics and the risk of alcoholism. JAMA 254:2614-2617.

Slater GG, Ziskind E (1973): Haptoglobins, group specific component, and an unknown polymorphic protein in mental disease. Fed Proc 32:598.

Tanna VL, Winokur G, Elston RC, Go RCP (1976a): A linkage study of depression spectrum disease: The use of the sib-pair method. Neuropsychobiology 2:52-62.

Tanna VL, Winokur G, Elston RC, Go RCP (1976b): A linkage study of pure depressive disease: The use of the sib-pair method. Biol Psychiatry 6:767-771.

Tanna VL, Go RCP, Winokur G, Elston RC (1977a): Possible linkage between group specific component (Gc protein) and pure depressive disease. Acta Psychiatr Scand 55:115.

Tanna VL, Winokur G, Elston RC, Go RCP (1977b): Blood markers and depressive disorders: An association study. Compr Psychiatry 18:263-269.

Tanna VL, Go RCP, Winokur G, Elston RC (1979): Possible linkage between $\alpha$-haptoglobin (Hp) and depression spectrum disease. Neuropsychobiology 5:102-113.

Tanna VL, Wilson AF, Winokur G, Elston RC (1989): Linkage of pure depressive disease. In press, J Psychiatric Res.

Wilson AF, Elston RC, Siervogel RM, Tran LD (1988): Linkage of a gene regulating dopamine$\beta$-hydroxylase activity and the ABO blood group locus. Am J Hum Genet 42:160-166.

Winokur G (1974): The division of depressive illness into depression spectrum disease and pure depressive disease. Int Pharmacopsychiatry 9:5-13.

Winokur G, Clayton P (1967): Family history studies. I. Two types of affective disorders separated according to genetic and clinical factors. Rec Adv Biol Psychiatry 10:35-50. 
Winokur G, Clayton P, Reich T (1969): Manic Depressive Illness. St. Louis: C.V. Mosby Company, pp 1-186.

Winokur G, Cadoret R, Dorzab J, Baker M (1971): Depressive disease-A genetic study. Arch Gen Psychiatry 24:135-144.

Winokur G, Cadoret R, Baker M, Dorzab J (1975): Depression spectrum disease versus pure depressive disease: Some further data. Br J Psychiatry 127:75-77. 